\title{
Fabrication of Fullerene-Reinforced Aluminum Matrix Nanocomposites
}

\author{
Hamed Asgharzadeh ${ }^{1}$ - Hamid Faraghi ${ }^{1}$ Hyoung Seop Kim ${ }^{2}$
}

Received: 25 March 2017/Revised: 17 May 2017/Published online: 14 July 2017

(C) The Chinese Society for Metals and Springer-Verlag GmbH Germany 2017

\begin{abstract}
Fullerene-reinforced Al matrix nanocomposites were fabricated by high-energy mechanical milling followed by consolidation through hot extrusion or high-pressure torsion (HPT). The results indicate that a relatively homogeneous microstructure consisting of elongated, micrometer-sized Al grains is formed in the hot-extruded specimens. However, the microstructure is not uniform along the radius of the HPT disks, which includes coarse grains near the center of the disk and ultrafine grains in the middle and along the edge of the specimen. Microstructural evaluations of the HPT disks indicate that $\mathrm{Al}$ grain refinement occurs due to the addition of fullerene, as grain size is reduced to $60 \mathrm{~nm}$ from $118 \mathrm{~nm}$. The formation of the harmful aluminum carbide phase is not detected during the fabrication of $\mathrm{Al} / \mathrm{C}_{60}$ nanocomposites. The hardness, yield stress, and ultimate tensile strength of the $\mathrm{Al}-2$ vol.\% $\mathrm{C}_{60}$ nanocomposites are about $27-160 \%$ higher than those of the monolithic Al samples, revealing the effective strengthening of fullerene particles in Al matrix. Moreover, mechanical properties of the Al/fullerene nanocomposites are significantly enhanced (59-272\%) by utilizing HPT in comparison to hot-extruded specimens due to their much finer $\mathrm{Al}$ grain structure. The reduction in the number and the size of the dimples, as well as the formation of smooth regions on the tensile fracture surface of $\mathrm{Al} / \mathrm{C}_{60}$, results in their overall lower ductility compared to monolithic Al.
\end{abstract}

KEY WORDS: Aluminum; Fullerene; High-pressure torsion; Hot extrusion; Microstructure; Mechanical properties

\section{Introduction}

Fullerenes are hollow carbon molecules in the form of a sphere (buckyballs) or tubes (carbon nanotubes: CNTs) [1]. Buckyballs can be essentially regarded as graphite layers, i.e., graphene sheets, wrapped into a spherical shape

Available online at http://link.springer.com/journal/40195

Hamed Asgharzadeh

asgharzadeh@tabrizu.ac.ir

1 Department of Materials Engineering, Faculty of Mechanical Engineering, University of Tabriz, Tabriz 51666-16471, Iran

2 Department of Materials Science and Engineering, Pohang University of Science and Technology (POSTECH), Pohang 790-784, South Korea instead of a cylindrical shape as in CNTs. Considering the staggering cost and limited availability of purified singlewalled carbon nanotubes, it is obvious that fullerenes with a spherical structure offer an interesting alternative to CNTs since they are available in abundance and at a much feasible cost. Furthermore, these fullerenes offer a high degree of purity and maintain their quality even during the subsequent reproduction cycles. [2-4]. Thus, fullerenes are currently widely investigated and have the potential for various technical applications [5].

A significant potential application of fullerenes would be as reinforcement in metallic alloys used in structural parts. It should be noted that buckyballs, such as $\mathrm{C}_{60}$ fullerenes, may be considered as fascinating reinforcements in comparison to CNT or graphene, due to their zero-dimensional geometry. They can be easily dispersed 
and are scarcely damaged during severe mechanical dispersion processes carried out in metal matrix composites (MMCs) [2-4, 6]. $\mathrm{C}_{60}$ fullerene-reinforced MMCs have been typically prepared using high-temperature processing methods, such as squeeze casting [7], liquid metal infiltration [8], co-deposition [9, 10], and powder metallurgy (PM) [11]. However, the interaction between $\mathrm{C}_{60}$ fullerene and metal has been one of the main issues in the research related to fullerene. Although the $\mathrm{C}_{60}$ fullerene might be considered as a chemically nonreactive molecule, it actually displays a significant reactivity with other atoms and molecules due to its icosahedral architecture that possesses both $s p^{2}$ and $s p^{3}$ bondings [12,13]. Furthermore, a harmful chemical reaction between fullerenes and metal matrix might be facilitated by the large surface area of fullerenes.

Among all MMCs, aluminum is the most commonly used metal as matrix owing to its high specific strength and stiffness, wear resistance, and electrical and thermal conductivities [8, 14]. To improve the mechanical properties of $\mathrm{Al}$ matrix MMCs, various reinforcements such as $\mathrm{Al}_{2} \mathrm{O}_{3}$ [15], $\mathrm{SiC}$ [16], $\mathrm{SiC} / \mathrm{Al}_{2} \mathrm{O}_{3}$ [17], $\mathrm{B}_{4} \mathrm{C}$ [18], $\mathrm{AlN}$ [19], $\mathrm{ZrO}_{2}$ [20], CNT [21], and graphene [22] have been used. Pioneering studies on $\mathrm{Al} / \mathrm{C}_{60}$ composites manufactured by casting and PM have been reported in Refs. $[2-4,11]$. These reports have hinted at the formation of the brittle aluminum carbide $\left(\mathrm{Al}_{4} \mathrm{C}_{3}\right)$ in the interface between $\mathrm{C}_{60}$ and Al matrix resulting in the premature fracture of the composite. Furthermore, the homogeneous dispersion has not occurred due to the inadequate diffusion in the solid state or the limited solubility of fullerene in $\mathrm{Al}$ in the liquid state [3]. Severe plastic deformation (SPD) techniques, e.g., equal channel angular pressing (ECAP), high-pressure torsion (HPT), accumulative roll bonding (ARB), and friction stir processing (FSP) provide an interesting alternative to casting and PM methods to overcome these setbacks. The manufacturing of fullerene-reinforced MMCs at low temperatures by utilizing SPD techniques hinders the formation of detrimental phases, homogeneously disperses the fullerene within the matrix, and significantly refines the matrix microstructure to the ultrafine size range $[23,24]$. Morisada et al. [25] have utilized FSP to fabricate AA5083/ $\left(\mathrm{C}_{60}+\mathrm{C}_{70}\right)$ composites and have reported that FSP increased the microhardness of the substrate by the promotion of the grain refinement phenomenon to $\sim 200 \mathrm{~nm}$ due to the pinning effect of the fullerene and its exceptionally high hardness. Tokunaga et al. [26] have consolidated a mixture of $\mathrm{C}_{60}$ and $\mathrm{C}_{70}$ fullerene with pure $\mathrm{Al}$ powder using HPT and have shown that the addition of fullerenes raised the tensile strength from about 150 to $250 \mathrm{MPa}$, whereas no meaningful effect in the elastic modulus was discovered.

The purpose of this work is to fabricate fullerene-reinforced $\mathrm{Al}$ matrix composites through the consolidation of a mixture of $\mathrm{Al}$ and $\mathrm{C}_{60}$ fullerene powders and to examine the influence of the fullerene addition on the microstructural evolution and tensile properties of Al. Although some researchers have investigated the microstructure and mechanical properties of fullerene-reinforced Al matrix composites, the effects of processing method on the grain structure of the matrix and the distribution of fullerene within the matrix of $\mathrm{Al} /$ fullerene composites have not been examined in detail. To investigate the roles of processing temperature and strain on the microstructure and mechanical properties, two methods of consolidation were employed: (a) hot powder extrusion and (b) room temperature HPT. To achieve a homogeneous dispersion of fullerene particles throughout the Al matrix, high-energy mechanical milling has also been used prior to the consolidation.

\section{Materials and Methods}

\subsection{Al/ $\mathbf{C}_{60}$ Powder Preparation}

The commercial purity Al powder (99\%, Norlin) with an average particle size of $63 \mu \mathrm{m}$ was used as the base metal, and fullerene $\mathrm{C}_{60}$ powder (99.9\%, Cheaptubes) with an outer diameter of $\sim 1 \mathrm{~nm}$ was used as the reinforcing phase of the composite. Fullerene was dispersed in ethanol via sonication for $1 \mathrm{~h}$, and then $\mathrm{Al}$ powder was added into the mixture and sonicated for $0.5 \mathrm{~h}$ to achieve Al-2 vol.\% fullerene powder mixture. The powder mixture was then dried at $60{ }^{\circ} \mathrm{C}$ for $4 \mathrm{~h}$. $1 \mathrm{wt} \%$ stearic acid $\left(\mathrm{CH}_{3}\left(\mathrm{CH}_{2}\right)_{16-}\right.$ $\mathrm{COOH}$, Merck) was added to the $\mathrm{Al} / \mathrm{C}_{60}$ powder as the process control agent in a $125-\mathrm{mL}$ volume vial made of hardened steel and mixed for $1 \mathrm{~h}$ in a low-energy ball mill. Hardened steel balls with diameters of 11 and $19 \mathrm{~mm}$ were put into the vial to achieve the ball-to-powder weight ratio of 10:1. High-energy mechanical milling of the composite powder was performed in a planetary ball mill with a rotational speed of $350 \mathrm{rpm}$ for $4 \mathrm{~h}$ in $\mathrm{Ar}$ atmosphere. For powder characterization, a small amount of the milled powder was taken out of the vial and stored in an argonfilled glove box.

\section{$2.2 \mathrm{Al} / \mathrm{C}_{60}$ Powder Consolidation}

The powder was degassed at $450{ }^{\circ} \mathrm{C}$ for $1 \mathrm{~h}$ in Ar atmosphere. The consolidation of the composite powder was performed via either HPT at room temperature or powder extrusion at an elevated temperature. For HPT consolidation, first the powder was pre-compacted into the diskshaped sample with a diameter and thickness of 10 and $1.5 \mathrm{~mm}$, respectively. Then, the disk was placed between HPT anvils with a circular shallow hole (diameter of 
$10 \mathrm{~mm}$ and depth of $0.25 \mathrm{~mm}$ ) and a pressure of $6 \mathrm{GPa}$ was applied. The HPT processing was conducted under a quasiconstrained condition by imposing severe plastic strains through ten revolutions at a rotating speed of $1 \mathrm{rpm}$. The processed disk had a thickness of $\sim 0.8 \mathrm{~mm}$ with some limited outward material flow between the upper and lower anvils.

To consolidate the powder by hot extrusion, the composite powder was filled in a 30-mm-diameter $\mathrm{Al}$ can and pre-compacted to a height of $\sim 70 \mathrm{~mm}$. After preheating at $450{ }^{\circ} \mathrm{C}$ for $30 \mathrm{~min}$, the compacted powder was extruded with an extrusion ratio of 9:1 into a 10-mm-diameter cylindrical billet. As a reference, the monolithic $\mathrm{Al}$ powder was mechanically milled and consolidated with the same procedure as described above.

\subsection{Microstructural Characterization}

The morphology of mechanically milled powders was examined by a scanning electron microscope (SEM, CX200, COXEM). X-ray diffraction (XRD) analysis was performed using a Siemens D500 diffractometer with $\mathrm{Cu}$ $K_{\alpha}$ radiation source working at the voltage of $40 \mathrm{kV}$ and the current of $30 \mathrm{~mA}$. The density of the consolidated powders was measured with a Mettler Toledo XP205 densimeter. For metallographic observations, the polished samples were etched using a solution of $1 \% \mathrm{HF}$ in distilled water, and the microstructure was observed by an Olympus BX61 optical microscope. Transmission electron microscopy (TEM) observations were performed on a crosssectional cut milled out from the HPT disk at a distance of $2.5 \mathrm{~mm}$ from the center using a focused ion beam (FIB) milling (3D total analysis, Helios Nanolab Dual Beam, FEI, Hillsboro), as shown in Fig. 1. TEM characterization was carried out using a JEOL JEM 2100F STEM operating

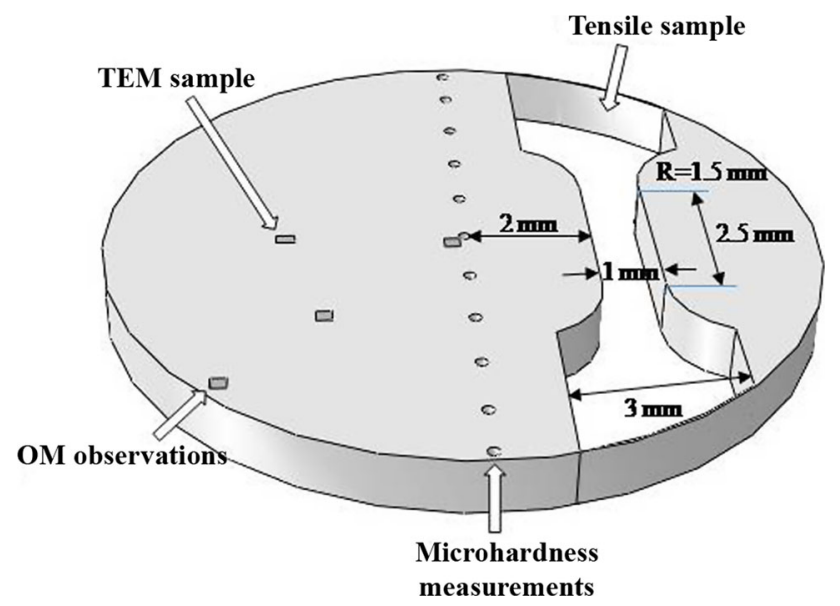

Fig. 1 Schematic illustration of HPT disk and locations for tensile samples, microhardness measurements, and OM and TEM observations at a voltage of $200 \mathrm{kV}$. The $\mathrm{Al}$ grain size was measured by the line intercept method.

\subsection{Mechanical Properties}

The microhardness of HPT disks was measured across the diameter of each disk with an applied load of $2.94 \mathrm{~N}$ using a Vickers indenter (Future-Tech FM-700), as illustrated in Fig. 1. The Vickers hardness of the powder extrudates was measured at a load of $0.49 \mathrm{~N}$. The hardness and microhardness measurements were performed at least three times each.

To investigate the tensile properties of the HPT disks, flat and dog bone-shaped microtensile specimens with a width of $1 \mathrm{~mm}$ and a gauge length of $1.5 \mathrm{~mm}$ were cut from the disks at $2.5 \mathrm{~mm}$ distance from the center using electro-discharge machining (EDM), as shown in Fig. 1. The round cross-sectional tensile specimens with a diameter of $4 \mathrm{~mm}$ and a gauge length of $16 \mathrm{~mm}$ were machined from the extrudates as well. The tensile test was conducted at room temperature at an initial strain rate of $\sim 10^{-3} \mathrm{~s}^{-1}$. Fracture surfaces resulted in the aftermath of the tensile test were examined on a JEOL JSM-6330F field emission scanning electron microscope (FE-SEM).

\section{Results and Discussion}

Figures 2 and 3 show the morphology and microstructure of $\mathrm{Al}$ and $\mathrm{Al} / \mathrm{C}_{60}$ powder particles. The gas-atomized $\mathrm{Al}$ powder exhibits mostly irregular morphology (Fig. 2a). The Al particles were flattened and had a flake-like morphology which was formed due to the impacts of the balls during mechanical milling for $4 \mathrm{~h}$ (Fig. 2b). Furthermore, Al flakes started to weld together forming large particles with an average size of $\sim 100 \mu \mathrm{m}$, as shown in Fig. 3a. It can be seen from Fig. $2 \mathrm{c}$ that for $\mathrm{Al} / \mathrm{C}_{60}$ powder, microwelding between the particles is more pronounced. On the other hand, a slight fragmentation of the flattened particles occurred so that the average size of particles was decreased to $\sim 80 \mu \mathrm{m}$ (Fig. $3 \mathrm{~b}$ ).

The XRD patterns of the $\mathrm{Al}$ and $\mathrm{Al} / \mathrm{C}_{60}$ powders are presented in Fig. 4. The diffraction patterns of the $\mathrm{Al}$ and $\mathrm{Al} / \mathrm{C}_{60}$ powders are similar and exhibit the typical reflections for $\mathrm{Al}$. Neither fullerene nor second phases were detected owing to their very low amount, well below the detection limit of the XRD method.

The densities of $\mathrm{Al}$ and $\mathrm{Al} / \mathrm{C}_{60}$ specimens after consolidation can be seen in Table 1 . It is clear that a high degree of densification with a relative density (the ratio of density to theoretical density) of more than $98 \%$ was achieved through both HPT and powder extrusion methods. Figure $5 \mathrm{a}, \mathrm{b}$ presents optical micrographs of the longitudinal 

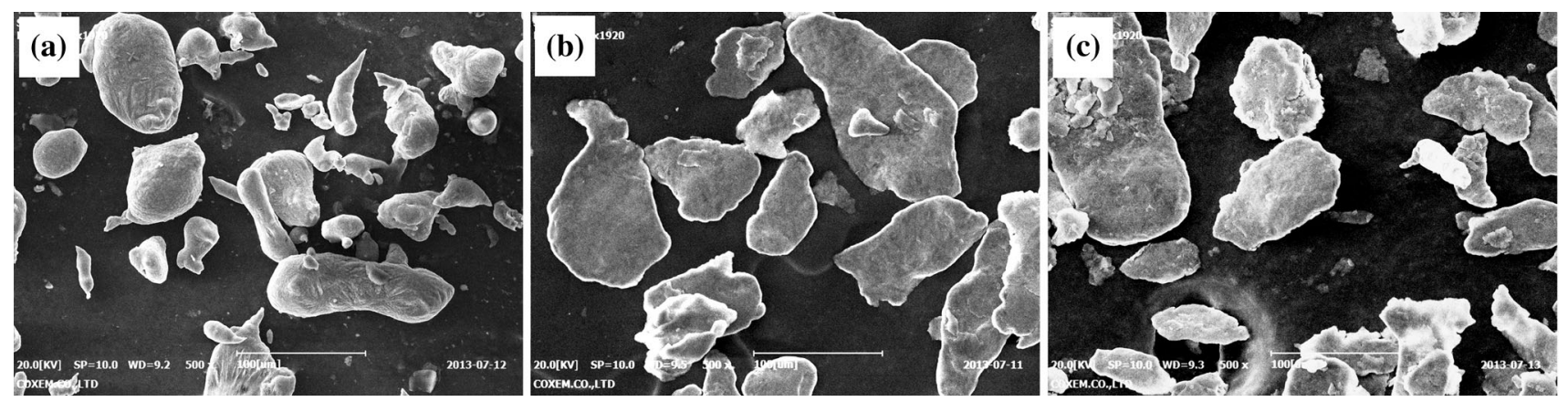

Fig. 2 SEM images of powders: a gas-atomized $\mathrm{Al}$; $\mathbf{b}$ mechanically milled $\mathrm{Al}$, c mechanically milled $\mathrm{Al} / \mathrm{C}_{60}$
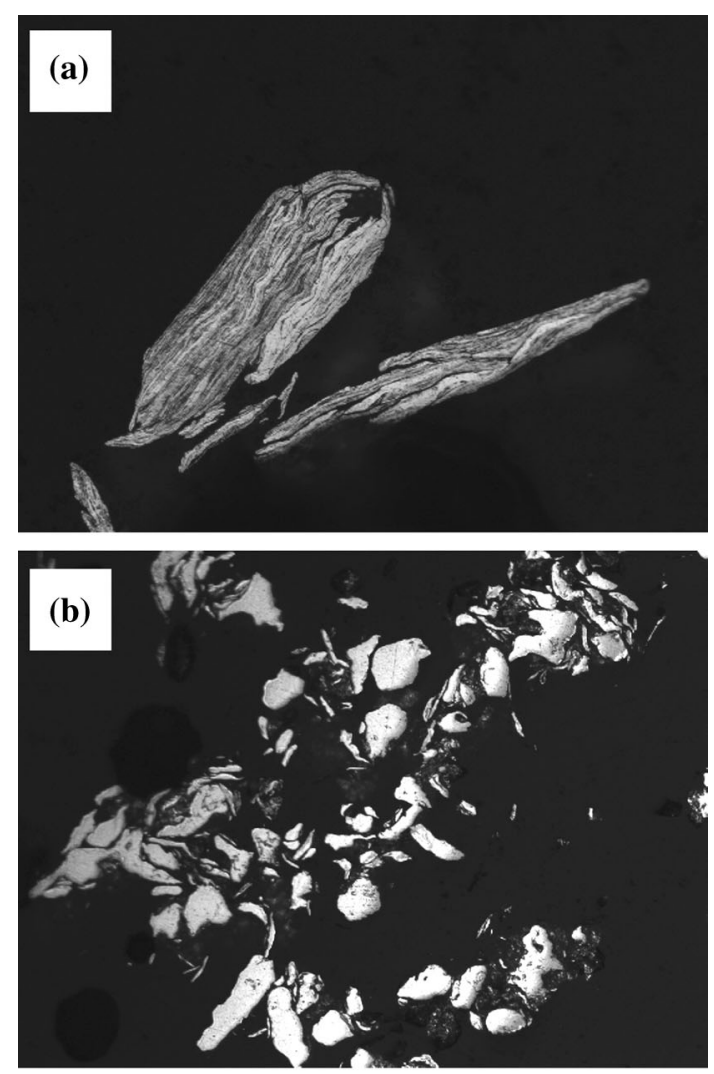

$200 \mu \mathrm{m}$

Fig. 3 Optical micrographs of mechanically milled powders: a $\mathrm{Al}$, b $\mathrm{Al} / \mathrm{C}_{60}$

cross sections of the $\mathrm{Al}$ and $\mathrm{Al} / \mathrm{C}_{60}$ extrudates. The microstructure of the hot-extruded specimens was extended parallel to the direction of extrusion so that elongated micrometer-sized Al grains were formed. No agglomerations of fullerenes were observed after hot extrusion. The microstructure of the top surface of ten revolutions HPT disks at different areas is shown in Fig. 5c-h. It is well known that for ideal rigid-body torsion, the center of the disk should not be subjected to any shear strain, and thus, the microstructure of the powder should be preserved in

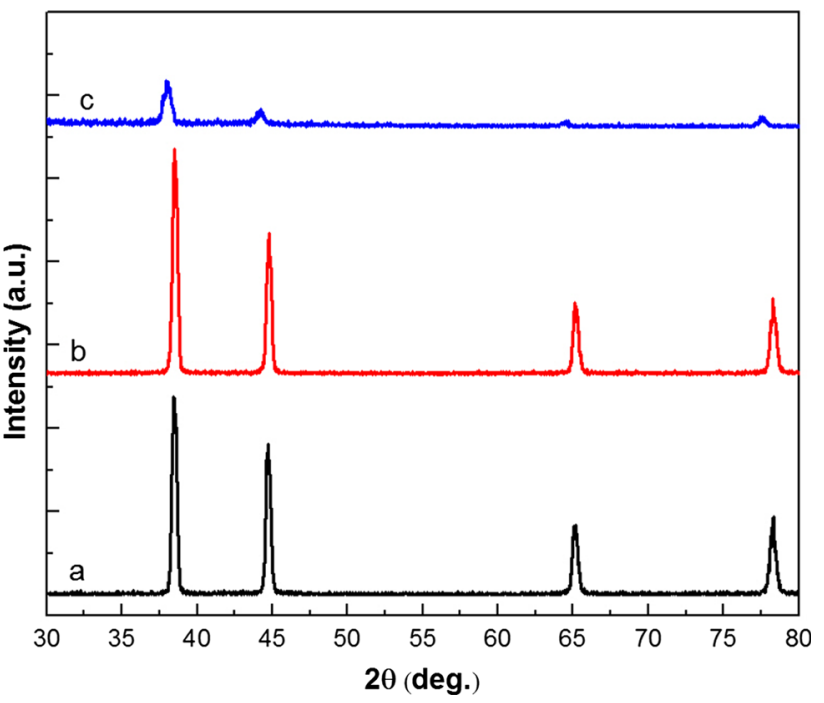

Fig. 4 XRD pattern of: a $\mathrm{Al}$ powder; b $\mathrm{Al} / \mathrm{C} 60$ powder; c $\mathrm{Al} / \mathrm{C}_{60}$ extrudate

this area. However, a moderate shear deformation is seen in the central area of the disk (Fig. 5c, d), especially in the case of monolithic Al, revealing the incidence of deviations from the ideal rigid-body torsion. Similar observation has been reported by $\mathrm{Cao}$ et al. [27]. Furthermore, a few small pores were detected in the central area of the disks. On the other hand, a circular macroscopic shear deformation pattern was observed in the other areas of the HPT disks. It is well established that the shear strain $(\gamma)$ increases in direct proportions with the distance from the torsion axis $(r)$, based on the following relationship [28]:

$\gamma=\frac{2 \pi N r}{h}$

where $N$ is the number of revolutions and $h$ is the thickness of the disk. Thus, a fully dense microstructure consisting of severely deformed particles would be observed at the middle $(r=2.5 \mathrm{~mm} ; \gamma=196)$ and near the periphery $(r=4.5 \mathrm{~mm} ; \gamma=353)$ areas (Fig. 5e-h). Also, the extent of deformation increases, as the distance from the center increases in agreement with Eq. (1). The equivalent von 
Table 1 Density, hardness, and tensile properties of Al and Al-2 vol.\% fullerene fabricated by high-pressure torsion and hot extrusion

\begin{tabular}{|c|c|c|c|c|c|c|c|}
\hline Material type & $\begin{array}{l}\text { Consolidation } \\
\text { method }\end{array}$ & $\begin{array}{l}\text { Density } \\
\left(\mathrm{g} \mathrm{cm}^{-3}\right)\end{array}$ & $\begin{array}{l}\text { Relative } \\
\text { density }\end{array}$ & $\begin{array}{l}\text { Hardness } \\
(\mathrm{HV})\end{array}$ & $\begin{array}{l}\text { Offset yield stress } \\
\text { (MPa) }\end{array}$ & $\begin{array}{l}\text { Ultimate tensile } \\
\text { strength (MPa) }\end{array}$ & $\begin{array}{l}\text { Strain to } \\
\text { fracture }(\%)\end{array}$ \\
\hline $\mathrm{Al}$ & HPT & $2.659 \pm 0.004$ & 0.985 & $92 \pm 1$ & 305 & 321 & 25.9 \\
\hline $\mathrm{Al}$ & Hot extrusion & $2.661 \pm 0.002$ & 0.986 & $30 \pm 3$ & 63 & 124 & 36 \\
\hline $\begin{array}{r}\text { Al-2 vol. } \% \\
\text { fullerene }\end{array}$ & HPT & $2.647 \pm 0.002$ & 0.984 & $139 \pm 2$ & 409 & 409 & 0.6 \\
\hline $\begin{array}{r}\text { Al-2 vol.\% } \\
\text { fullerene }\end{array}$ & Hot extrusion & $2.655 \pm 0.003$ & 0.983 & $78 \pm 9$ & 110 & 258 & 14.1 \\
\hline
\end{tabular}

Mises strain $(\varepsilon)$ for the HPT and extrusion processes can be calculated using Eqs. (2) and (3), respectively [29]:

$\varepsilon=\frac{\gamma}{\sqrt{3}}$,
$\varepsilon=\ln R$,

where $R$ is the extrusion ratio. Here, since the equivalent von Mises strain varied from 0 to 245 for the HPT process, it had a constant value of 2.2 for extrusion. Thus, the microstructural changes are mostly related to the amount and uniformity of the imposed strain during the consolidation.

The detailed microstructure analysis for the HPT-processed $\mathrm{Al}$ and $\mathrm{Al} / \mathrm{C}_{60}$ specimens was conducted using TEM. Bright-field TEM micrographs and corresponding selected area diffraction (SAED) patterns are shown in Fig. 6. A significant grain refinement occurred after HPT processing for ten revolutions so that ultrafine grain structure was attained in both monolithic $\mathrm{Al}$ and $\mathrm{Al} / \mathrm{C}_{60}$ composites. $\mathrm{A}$ relatively equiaxed grain structure with an average grain size of $\sim 118 \mathrm{~nm}$ was formed in monolithic $\mathrm{Al} \mathrm{(Fig.} \mathrm{6a).}$ Microstructural refinement is more pronounced in $\mathrm{Al} / \mathrm{C}_{60}$ composite, and the average grain size was measured as $\sim 60 \mathrm{~nm}$. Moreover, as shown in Fig. 6b, most of the grains are flattened in a direction perpendicular to the compression axis having dimensions of $33 \mathrm{~nm} \times 86 \mathrm{~nm}$. The greater grain refinement of $\mathrm{Al} 6061 / \mathrm{SiC}$ [30] and $\mathrm{Al} /(\mathrm{CNT}$, graphene) [31] in comparison to the monolithic metal during the HPT processing has been previously stated.

The finer grain size of the $\mathrm{Al}$ matrix in $\mathrm{Al} / \mathrm{C}_{60}$ composite is also reflected in the SAED patterns. The SAED pattern of monolithic $\mathrm{Al}$ contains separate spots indicating the presence of low-angle grain boundaries (Fig. 6c). Conversely, the SAED pattern in Fig. 6d consists of more diffraction spots than that in Fig. 6c. These spots situated around circles forming continuous diffraction rings represent the existence of a large amount of high-angle grain boundaries [29]. In both cases, the azimuthal spreading of some spots in the SAED patterns discloses the existence of high internal stresses induced by severe straining through HPT [32]. Figure 7a illustrates the high-angle angular- dark-field (HAADF) TEM micrograph of $\mathrm{Al} / \mathrm{C}_{60}$ nanocomposite. It can be seen that fullerene uniformly dispersed within the Al matrix. The high-resolution TEM (HRTEM) image as shown in Fig. $7 \mathrm{~b}$ indicates that no detrimental phases, e.g., $\mathrm{Al}_{4} \mathrm{C}_{3}$, were formed in the microstructure of the $\mathrm{Al} / \mathrm{C}_{60}$ composite.

Figure 8 shows the variation of the Vickers microhardness with position on the $\mathrm{Al}$ and $\mathrm{Al} / \mathrm{C}_{60}$ disks subjected to HPT for ten revolutions under the pressure of $6 \mathrm{GPa}$. It is clear that $\mathrm{Hv}$ values tend to grow in proportion to the distance from the center of the disk, especially for $\mathrm{Al} / \mathrm{C}_{60}$ composite. However, the rate at which microhardness increases is greater near the center of the disk so there is a tendency toward saturation in Hv near the periphery of the disk. This is a typical behavior in HPT processing for a material with slow recovery rate, where the hardness is initially lower in the center, but the microstructure gradually evolves into a homogeneous condition [33]. Thus, for both monolithic $\mathrm{Al}$ and $\mathrm{Al} / \mathrm{C}_{60}$ composites, the microstructure was not completely evolved after ten revolutions, which is in agreement with Fig. 5c-h. Furthermore, higher imposed strains are necessary for microstructural homogeneity and hardness saturation.

The hardness level of the $\mathrm{Al} / \mathrm{C}_{60}$ composite is invariably higher than that of the monolithic $\mathrm{Al}$, so that the average hardness value throughout the disk is $51 \%$ higher in the composite sample. This situation is much more significant in the hot-extruded samples, since reinforcing of $\mathrm{Al}$ with fullerene increased the average hardness about 2.6 times (Table 1). It should also be noted that the hardness values for extrudates are much lower than HPT samples, mostly due to their coarse grain structure.

Tensile tests of the samples have demonstrated a strong effect of the fullerene addition and processing method on the strength and ductility of Al. The measured yield stress (YS), ultimate tensile strength (UTS), and strain to fracture (SF) values are listed in Table 1. It is obvious that YS and UTS values are in accordance with the hardness values. The highest YS and UTS values were observed for the $\mathrm{Al} /$ $\mathrm{C}_{60}$ composite processed via HPT (409 $\mathrm{MPa}$ ), being 34 and $27 \%$ higher than those of monolithic Al, respectively. Such 

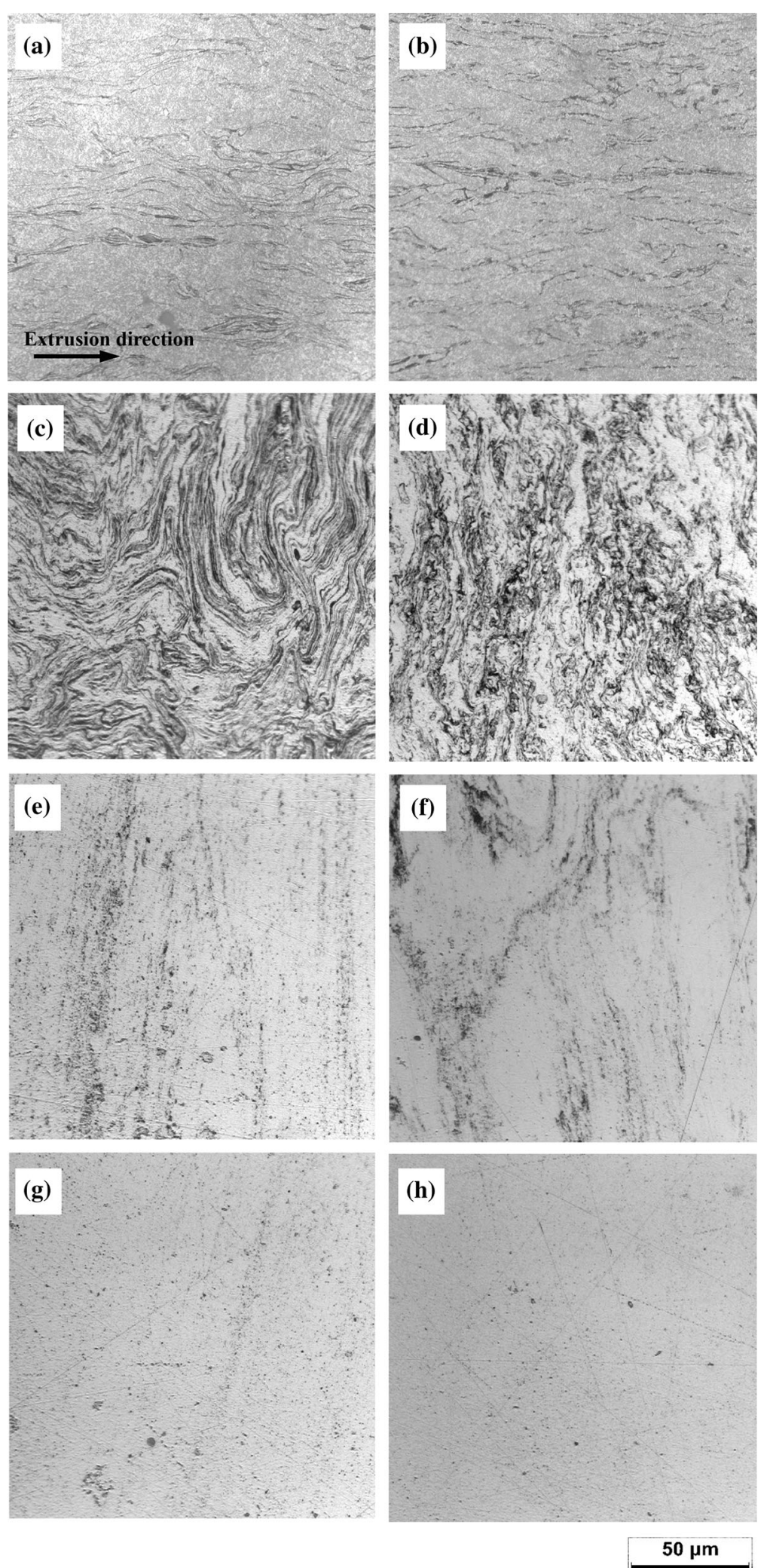

Fig. $5 \mathrm{OM}$ micrographs of hot-extruded and HPT-processed specimens: a $\mathrm{Al}$, hot extrusion; $\mathbf{b} \mathrm{Al} / \mathrm{C}_{60}$, hot extrusion; $\mathbf{c} \mathrm{Al}, \mathrm{HPT}$-center; $\mathbf{d} \mathrm{Al} / \mathrm{C}_{60}$, HPT-center; e Al, HPT-middle; f Al/C 60 , HPT-middle; g Al, HPT-edge; h Al/C 60 , HPT-edge 

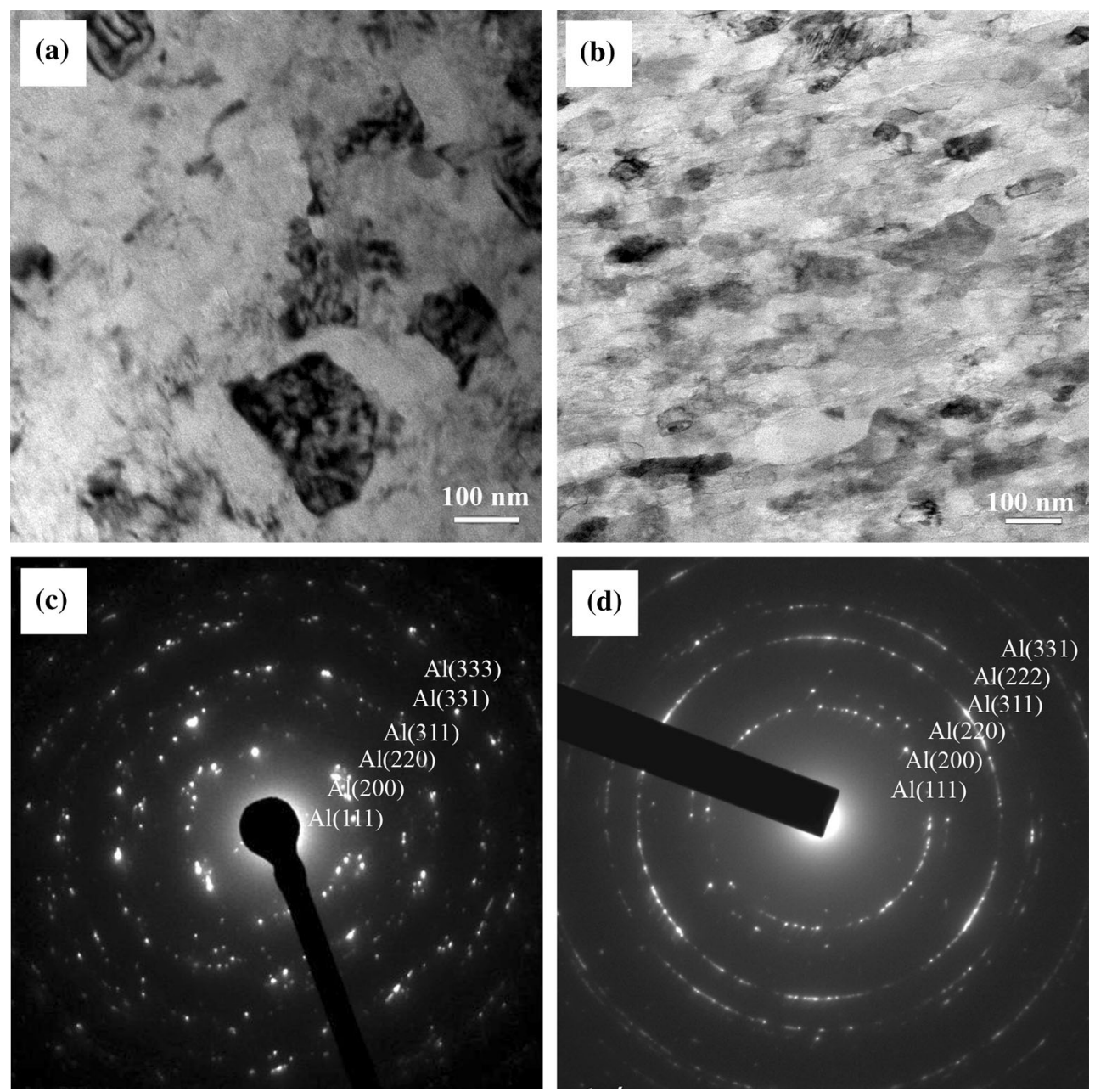

Fig. 6 TEM images and SAD patterns from the microstructure of the samples subjected to HPT for ten turns: a, $\mathbf{c} A 1, \mathbf{b}, \mathbf{d ~ A l / C _ { 6 0 }}$

high levels of strength improvement in the $\mathrm{Al} / \mathrm{C}_{60}$ composite can be attributed to the ultra-high strength of fullerene, the uniform dispersion of fullerenes within the $\mathrm{Al}$ matrix, the strong interfacial bonding between fullerenes and $\mathrm{Al}$ matrix, and the significant grain refinement of the $\mathrm{Al}$ matrix. It is pertinent to point out that the strength of the HPT-processed monolithic $\mathrm{Al}$ is much higher than those of the hot-extruded $\mathrm{Al}$ and even the $\mathrm{Al} / \mathrm{C}_{60}$ composite, revealing the significant role of nano-sized grain structure on the strengthening of Al. It should be noted that in the case of HPT specimens, the tensile samples were cut at a position $2.5 \mathrm{~mm}$ from the center of disks. Thus, the tensile properties of the HPT specimens are mostly the representative of the mechanical behavior of the middle regions of the disks. The inhomogeneous microstructure of the HPT disks which resulted from the heterogeneous nature of flow in HPT processing is likely accompanied by local variations in the tensile behavior of the samples similar to the hardness variations. Nevertheless, even though the hardness heterogeneity in HPT disks was extensively studied, the heterogeneity in their tensile properties has not been reported owing to the difficulties in the sample preparation and testing. In the case of hot-extruded samples, YS and UTS values for the $\mathrm{C}_{60}$-reinforced $\mathrm{Al}$ are 75 and $108 \%$ higher than those for $\mathrm{Al}$ without reinforcement, respectively, indicating the significant effect of fullerene on the strength enhancement. To better realize the influence of fullerenes, the strengthening efficiency $(\eta)$ was calculated according to the following equation [34]:

$\eta=\frac{\sigma_{\mathrm{c}}-\sigma_{\mathrm{m}}}{V_{\mathrm{f}} \sigma_{\mathrm{m}}}$,

where $\sigma_{\mathrm{c}}$ and $\sigma_{\mathrm{m}}$ are the UTS values of composite and monolithic material, respectively, and $V_{\mathrm{f}}$ is the volume fraction of the reinforcement. The strengthening efficiency values of fullerene in Al matrix in the HPT and hot-extruded samples are 13.7 and 54, respectively. Note that these values are larger than those obtained previously for press-sintered Al-8 vol. $\% \mathrm{C}_{60}+\mathrm{C}_{70}$ (9.1) [2], press-sintered Al-1.3 vol.\% fullerene (48.4) [3], spark plasma-sintered Al-20 vol.\% $\mathrm{C}_{60}+\mathrm{C}_{70}$ (24.2) [4], and HPTprocessed Al-5 wt $\% \mathrm{C}_{60}+\mathrm{C}_{70}$ (8.9) [26]. 

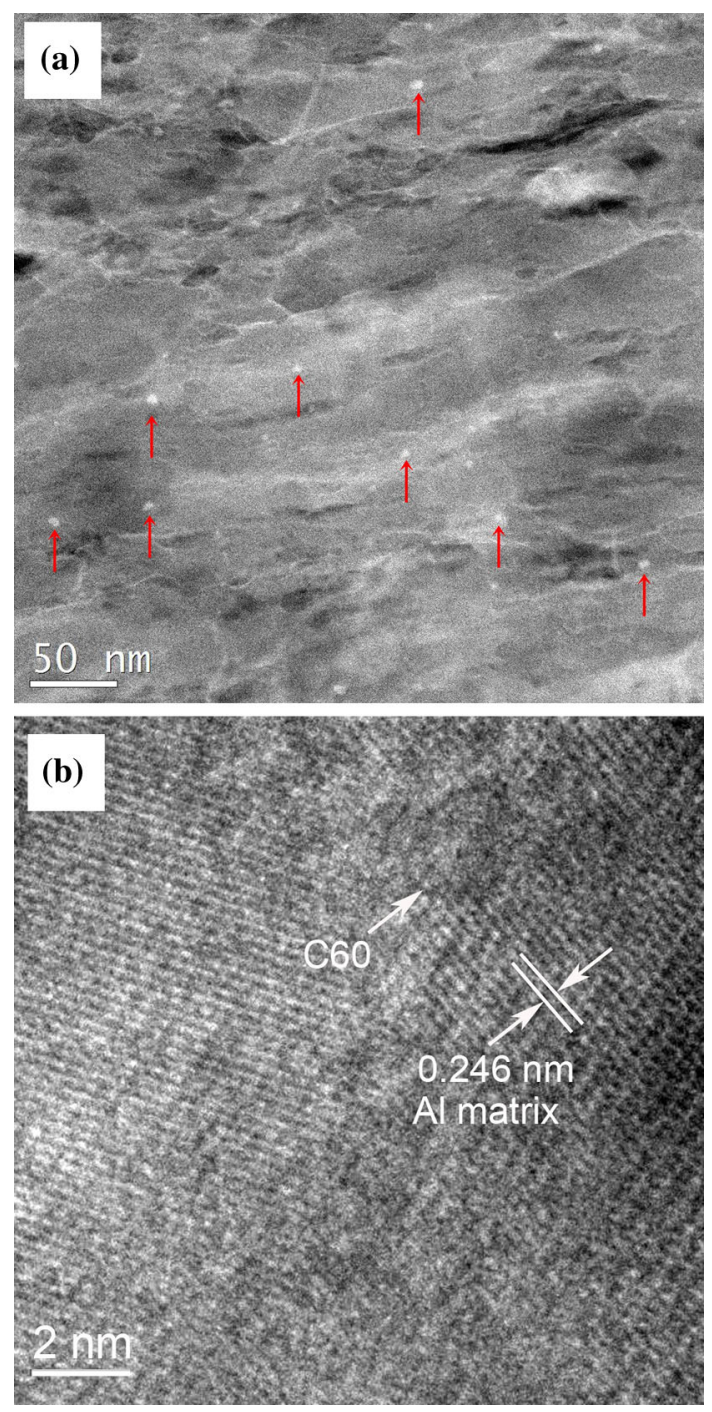

Fig. 7 a HAADF TEM, b HRTEM images of HPT-processed $\mathrm{Al} / \mathrm{C}_{60}$ nanocomposite. The arrows in a show fullerene within the $\mathrm{Al}$ matrix

In contrast to the effective influence of the addition of fullerene into the $\mathrm{Al}$ matrix as reinforcing agent, it had a detrimental effect on the strain to fracture ratio. The fracture surfaces of $\mathrm{Al}$ and $\mathrm{Al} / \mathrm{C}_{60}$ samples resulting from tensile testing were studied using SEM (Fig. 9). The hotextruded monolithic Al specimen displayed a dimpled surface typical for intragranular ductile fracture mode (Fig. 9a, b). The dimples are mostly equiaxed with a mean size of $\sim 3 \mu \mathrm{m}$. A sharp decrease in the size of the ductile dimples to $\sim 100-300 \mathrm{~nm}$ was observed on the fracture surface of the monolithic Al processed by HPT, as clearly seen in Fig. 9d. The size of dimples is in agreement with the grain size of the sample (Fig. 6a). Furthermore, several smooth regions were detected on the fracture surface

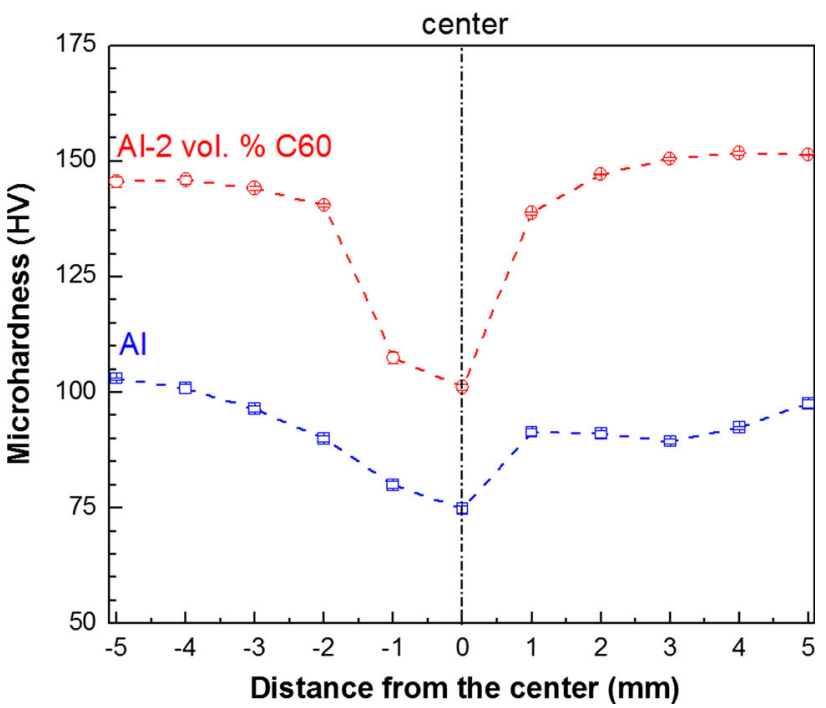

Fig. 8 Variation of Vickers microhardness with distance from the center of the HPT disks

(Fig. 9c). These fracture surface features indicate that the ductility of the HPT Al sample should be considerably diminished compared with the hot-extruded sample. This result is well consistent with the tensile testing results given in Table 1. By comparing the hot-extruded monolithic $\mathrm{Al}$ (Fig. 9a, b) and $\mathrm{Al} / \mathrm{C}_{60}$ composite (Fig. 9e, f) samples, a remarkable change in the morphology of the fracture surface was observed. The amount of dimples was significantly reduced, and a layered morphology consisting of weakly bonded powder particles was monitored on the fracture surface of $\mathrm{Al} / \mathrm{C}_{60}$. This observation may be attributed to the employment of improper processing conditions during hot extrusion of this sample, e.g., low imposed strain and temperature, resulting in the deterioration of ductility. The fracture surface morphology of the HPT-processed $\mathrm{Al} / \mathrm{C}_{60}$ composite (Fig. $9 \mathrm{~g}, \mathrm{~h}$ ) is similar to that of the monolithic $\mathrm{Al}$ (Fig. 9c, d) except that the size of dimples is reduced and the amount of smooth regions is increased. Additionally, some cracks were observed on the fracture surface which may be formed due to the poor interface between the fullerene cluster and the $\mathrm{Al}$ matrix, which acted as the crack nucleation sites. Under the tensile loading, these cracks propagated, accounting for the inferior ductility of the sample $(<1 \%)$. Similar results have been reported in the case of $\mathrm{Al} /$ fullerene composite fabricated by HPT [26] and AA6061/graphene composite prepared by semisolid sintering [35]. Thus, the ductility decrease in the $\mathrm{Al} / \mathrm{C}_{60}$ composite was most likely due to the fullerene addition and its dispersion rather than solely from the hardening effect caused by high-energy mechanical milling or consolidation, especially HPT processing. 

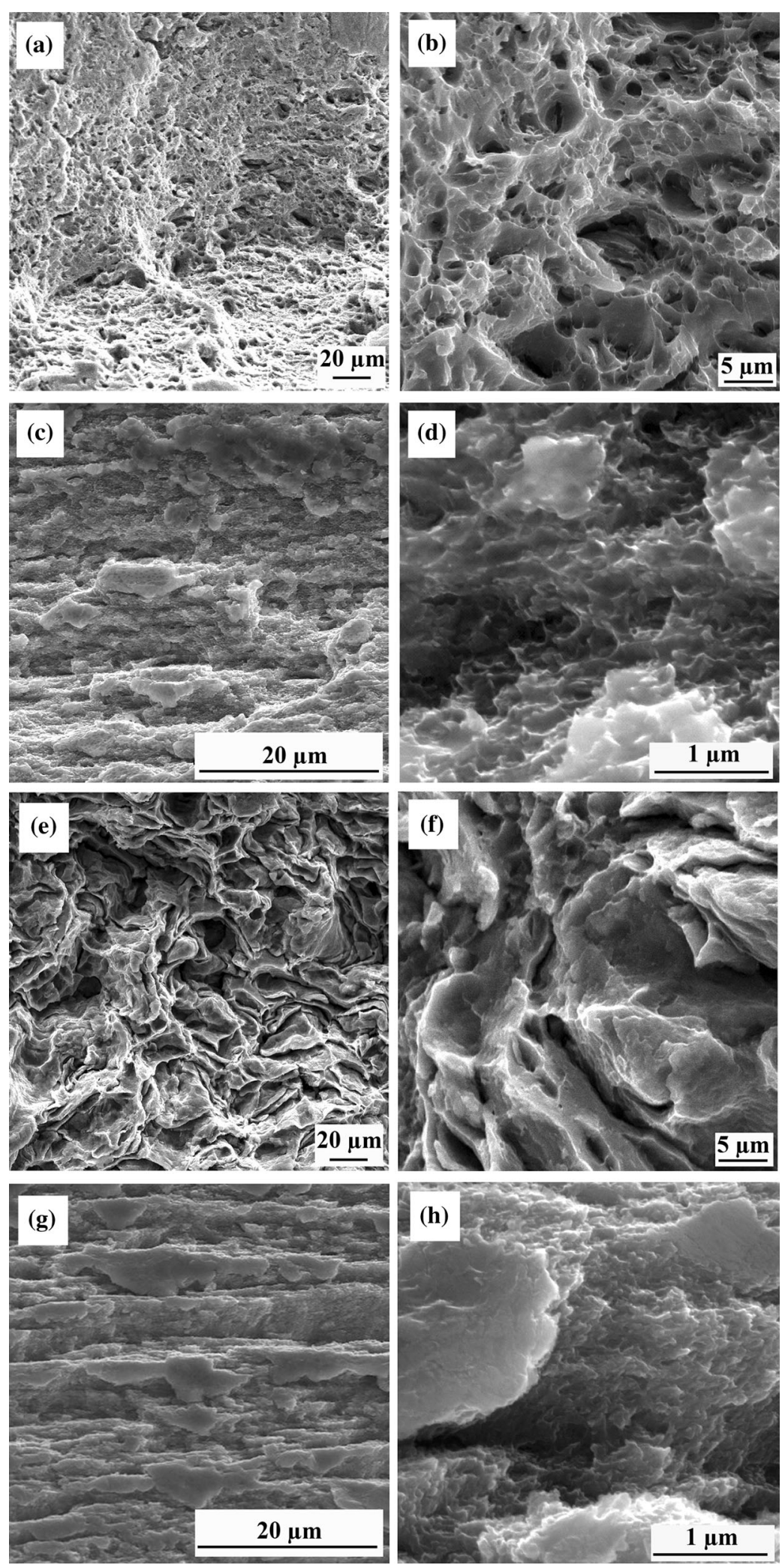

Fig. 9 Tensile fracture surfaces of $\mathrm{Al}$ and $\mathrm{Al} / \mathrm{C}_{60}$ samples at two different magnifications: a, b $\mathrm{Al}$, hot extrusion; $\mathbf{c}, \mathbf{d ~ A l}, \mathrm{HPT} ; \mathbf{e}, \mathbf{f} \mathrm{Al} / \mathrm{C} 60$, hot extrusion; g, h $\mathrm{Al} / \mathrm{C}_{60}, \mathrm{HPT}$ 


\section{Conclusions}

Near full density Al-2 vol.\% $\mathrm{C}_{60}$ nanocomposite samples were prepared from mechanically milled $\mathrm{Al}$ and fullerene powder mixtures by either hot extrusion or HPT. The main conclusions can be drawn as follows:

1. An inhomogeneous microstructure consisting of moderately to severely deformed $\mathrm{Al}$ grains was formed after HPT due to the variation of the imposed shear strain along the radius of the consolidated disk. Nevertheless, the microstructure of the hot-extruded sample was entirely composed of elongated Al grains.

2. A micrometer-sized grain structure with a thickness of $\sim 3 \mu \mathrm{m}$ was formed after hot extrusion. However, a significant grain refinement to nanoscale range (average grain thickness of $\sim 33 \mathrm{~nm}$ ) occurred in the HPT of $\mathrm{Al} / \mathrm{C}_{60}$ nanocomposite due to the application of severe plastic deformation.

3. The hardness and strength of $\mathrm{Al} / \mathrm{C}_{60}$ nanocomposite were much higher than those of the monolithic Al. The strengthening efficiency of fullerene in the Al matrix for the hot-extruded sample was greater than that for the HPT sample.

4. The fracture surface morphology of the HPT-processed $\mathrm{Al} / \mathrm{C}_{60}$ nanocomposite consisted of equiaxed ultrafine dimples and some cracks. Nonetheless, a layered morphology comprised of weakly bonded particles with some coarse dimples was observed on the fracture surface of hot-extruded sample. Thus, the addition of fullerene had a detrimental effect on the ductility of the monolithic Al.

Acknowledgement This work has been supported by the Center for International Scientific Studies and Collaboration (CISSC).

\section{References}

[[1] A. Aqel, K.M. Abou El-Nour, R.A. Ammar, A.A. Warthan, Arab. J. Chem. 5, 1 (2012)

[2] E.V. Barrera, J. Sims, D.L. Callahan, J. Mater. Res. 9, 2662 (1994)

[3] E.V. Barrera, J. Sims, D.L. Callahan, J. Mater. Res. 10, 366 (1995)

[4] V.G. Febles, H.A. Calderon, F.C. Hernandez, M. Umemoto, K. Masuyama, J.G. Cabanas Moreno, Mater. Manuf. Process. 15, 547 (2000)

[5] Y.I. Prilutski, S.S. Durov, Phys. Solid State 41, 802 (1999)

[6] W. Krätschmer, L.D. Lamb, K. Fostiropoulos, D.R. Huffman, Nature 347, 354 (1990)
[7] H. Uozumi, K. Kobayashi, K. Nakanishi, T. Matsunaga, K. Shinozaki, H. Sakamoto, T. Tsukada, C. Masuda, M. Yoshida, Mater. Sci. Eng., A 459, 282 (2008)

[8] F. Khalid, O. Beffort, U. Klotz, B. Keller, P. Gasser, S. Vaucher, Acta Mater. 51, 4575 (2003)

[9] H. Takahashi, E. Matsubara, M. Shiro, S. Matsubara, N. Sato, A. Muramatsu, K. Tohji, Fuller. Nanotub. Carbon Nanostruct. 10, 217 (2002)

[10] T. Toccoli, A. Boschetti, C. Corradi, L. Guerini, M. Mazzola, S. Iannotta, Synth. Met. 138, 3 (2003)

[11] K. Choi, J. Seo, D. Bae, H. Choi, Trans. Nonferr. Met. Soc. 24, s47 (2014)

[12] J. Vacik, V. Lavrentiev, K. Novotna, L. Bacakova, V. Lisa, V. Vorlicek, R. Fajgar, Diam. Relat. Mater. 19, 242 (2010)

[13] J.G. Hou, X. Li, H. Wang, B. Wang, J. Phys. Chem. Solids 61, 995 (2000)

[14] H. Asgharzadeh, S.H. Joo, H.S. Kim, Metall. Mater. Trans. A 46, 1838 (2015)

[15] H. Asgharzadeh, A. Simchi, H.S. Kim, Metall. Mater. Trans. A 42, 816 (2011)

[16] H. Asgharzadeh, A. Simchi, Powder Metall. 52, 28 (2009)

[17] M. Megahed, M.A. Attia, M. Abdelhameed, A.G. El-Shafei, Acta Metall. Sin. Engl. Lett. (2017). doi:10.1007/s40195-0170568-5

[18] H.S. Chen, W.X. Wang, H.H. Nie, Y.L. Li, Q.C. Wu, P. Zhang, Acta Metall. Sin. Engl. Lett. 28, 1214 (2015)

[19] H. Abdoli, H. Asgharzadeh, E. Salahi, J. Alloys Compd. 473, 116 (2009)

[20] S.E. Hernández-Martínez, J.J. Cruz-Rivera, R. Martínez-Sánchez, C.G. Garay-Reyes, J.A. Muñoz-Bolaños, J.M. Cabrera, J.L. Hernández-Rivera, Acta Metall. Sin. Engl. Lett. 29, 895 (2016)

[21] C.N. He, C. Feng, J.C. Lin, E.Z. Liu, C.S. Shi, J.J. Li, N.Q. Zhao, Acta Metall. Sin. Engl. Lett. 29, 188 (2016)

[22] J.M. Ju, G. Wang, K.H. Sim, J. Alloys Compd. 704, 585 (2017)

[23] C.P. Wang, F.G. Li, L. Wang, H.J. Qiao, Sci. China Technol. Sci. 55, 2377 (2012)

[24] T.C. Lowe, R.Z. Valiev, JOM 56, 64 (2004)

[25] Y. Morisada, H. Fujii, T. Nagaoka, K. Nogi, M. Fukusumi, Compos. A 38, 2097 (2007)

[26] T. Tokunaga, K. Kaneko, K. Sato, Z. Horita, Scr. Mater. 58, 735 (2008)

[27] Y. Cao, Y.B. Wang, R.B. Figueiredo, L. Chang, X.Z. Liao, M. Kawasaki, W.L. Zheng, S.P. Ringer, T.G. Langdon, Y.T. Zhu, Acta Mater. 59, 3903 (2011)

[28] R.Z. Valiev, Y.V. Ivanisenko, E.F. Rauch, B. Baudelet, Acta Mater. 44, 4705 (1996)

[29] A.P. Zhilyaev, T.G. Langdon, Prog. Mater Sci. 53, 893 (2008)

[30] C. Xu, Z. Horita, T.G. Langdon, Mater. Sci. Forum 667-669, $689(2011)$

[31] L. Zhao, H. Lu, Z. Gao, Adv. Eng. Mater. 17, 976 (2014)

[32] A.P. Zhilyaev, S. Lee, G.V. Nurislamova, R.Z. Valiev, T.G. Langdon, Scr. Mater. 44, 2753 (2001)

[33] C. Xu, Z. Horita, T.G. Langdon, Acta Mater. 55, 203 (2007)

[34] H.J. Ryu, S.I. Cha, S.H. Hong, J. Mater. Res. 18, 2851 (2003)

[35] M. Bastwros, G.Y. Kim, C. Zhu, K. Zhang, S. Wang, X. Tang, Compos. A 60, 111 (2014) 